\title{
Difficulties and Technical System in the Field of High Temperature and High Pressure
}

\author{
Peng Xuan*, Zhou Wei, Li Jia, Peng Xiaodong, Wang Yongbiao \\ CNOOC Ltd._Zhanjiang Research Institute, Zhanjiang, China

\section{Email address:} \\ pengxuan1@cnooccomen (Peng Xuan), zhouwei11@cnooccomcn (Zhou Wei), lijia11@cnooccomen (Li Jia), \\ pengxd@cnooccomcn (Peng Xiaodong), wangyb17@cnooccomcn (Wang Yongbiao) \\ ${ }^{*}$ Corresponding author
}

\section{To cite this article:}

Peng Xuan, Zhou Wei, Li Jia, Peng Xiaodong, Wang Yongbiao. Difficulties and Technical System in the Field of High Temperature and High Pressure. International Journal of Oil, Gas and Coal Engineering. Vol. 8, No. 3, 2020, pp. 58-67. doi: 10.11648/j.ogce.20200803.12

Received: May 10, 2020; Accepted: June 4, 2020; Published: June 28, 2020

\begin{abstract}
The field of high temperature and high pressure is a key area of oil and gas exploration and development in China in the future, and it is also a very rich area of oil and gas resources. Unlike conventional oil and gas fields, high-temperature and high-pressure oil and gas fields are characterized by high-pressure systems, overlapping sand bodies and more complex gas-water modes. How to effectively predict the pressure, clear the distribution of sand and water, guide the smooth implementation of drilling operations, reasonable development plan is a key step. The authors analyze the reservoir in detail from pre-drilling pressure modeling technique, reservoir fluid fine identification and reservoir formation mechanism respectively. Finally, the Dongfang M gas field has a good effect after drilling, and the output and production capacity are all over expectations, especially for the development effect of low permeability breaking the ceiling of traditional low permeability reservoir development, and form a high temperature and high pressure implementation technology system to guide the subsequent development of similar areas.
\end{abstract}

Keywords: High Temperature and High Pressure, Pressure Modeling, Gas-Water Model

\section{Introduction}

Yinggehai Basin is located between Hainan Island and Indo-Chinese Peninsula, and the basin is generally north-west-south-east strike, with long spindles (Figure 1). The basin is characterized by rapid subsidence filling, high ground temperature and high temperature gradient, large-scale abnormal pressure system and hot fluid bottom $[1,2]$. According to the regional sedimentary background and sequence stratigraphy, sedimentary facies characteristics and Characteristics of paleo-morphology and paleo-flow characteristics, seismic facies interpretation, etc., it is considered that the Huangliu formation is a set of strata deposited in the background of large-scale transgression after large-scale regression [3]. The overall sedimentary characteristics of the region provide a good place for the development of submarine fans, and the reservoir sedimentary facies are different from the classical submarine fan deposition patterns, which are manifested as the thick accumulation of waterway sand body combination patterns.

The target layer of Dongfang $\mathrm{M}$ gas field is $\mathrm{H}_{1} \mathrm{~A}, \mathrm{H}_{1} \mathrm{~B}$ sand body, the buried depth of sand body is about $3000 \mathrm{~m}$, its temperature gradient is $4.17^{\circ} \mathrm{C} / 100 \mathrm{~m}$, is abnormal high temperature system, and the reservoir temperature is $138^{\circ} \mathrm{C} \sim 143$, with an average of about $141^{\circ} \mathrm{C}$. The reservoir pressure coefficient is $1.90 \sim 1.94$, and the average is about 1.92, which is an abnormal high pressure system. The reservoir pressure is $53.5 \mathrm{MPa} \sim 54.1 \mathrm{MPa}$ [4]. It is not only the implementation of the first high temperature and high pressure gas field in the western sea area of the South China Sea, but also the experimental field to find high quality reservoirs under the new submarine fan deposition system.

\section{Geological Model Before Drilling}

\subsection{Establishment of Pressure Model}

Dongfang $\mathrm{M}$ gas field is the first high temperature and high pressure gas field in the west of the South China Sea, and there 
is no experience to learn from it. Among them, pressure prediction is the key factor of success or failure. The traditional pressure prediction method is obviously not suitable for high temperature and high pressure fine implementation. Combined with the geological characteristics and data degree of Dongfang $M$ gas field, it is difficult to achieve the ideal modeling effect by relying solely on drilling data because of the small drilling data in the working area [5, 6]. It is considered that the seismic inversion wave impedance attribute has a very good correlation with well point acoustic velocity (Figure 1), and the lithology based on well data statistics also has a good correlation with seismic inversion wave impedance attribute (Figure 2). Therefore, the pressure coefficient and lithologic distribution of reservoir are predicted by a combination of deterministic modeling and random simulation of seismic attributes, and the pressure coefficient model and lithologic probability model are established by using core and logging information as hard information and seismic data as soft information.

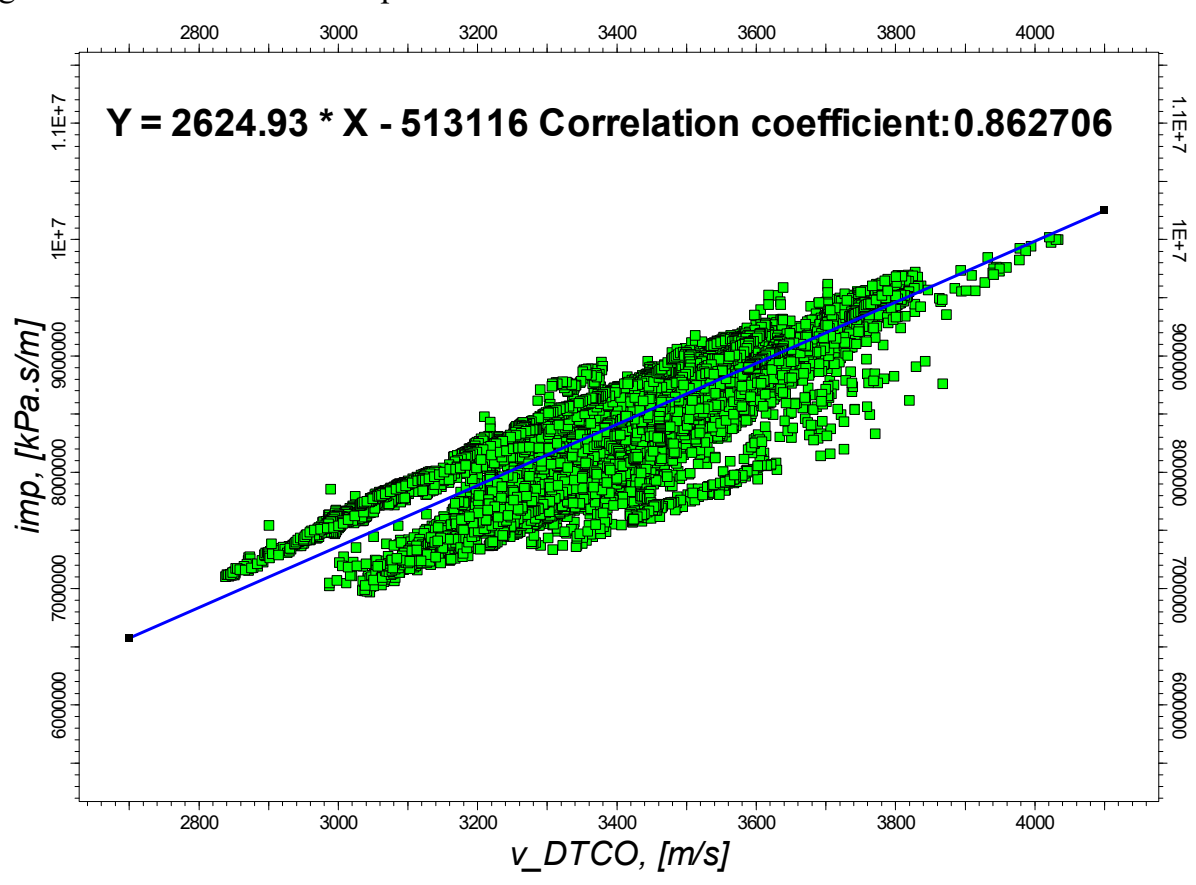

Figure 1. Based on the well point of acoustic velocity and wave impedance crossplot (left).

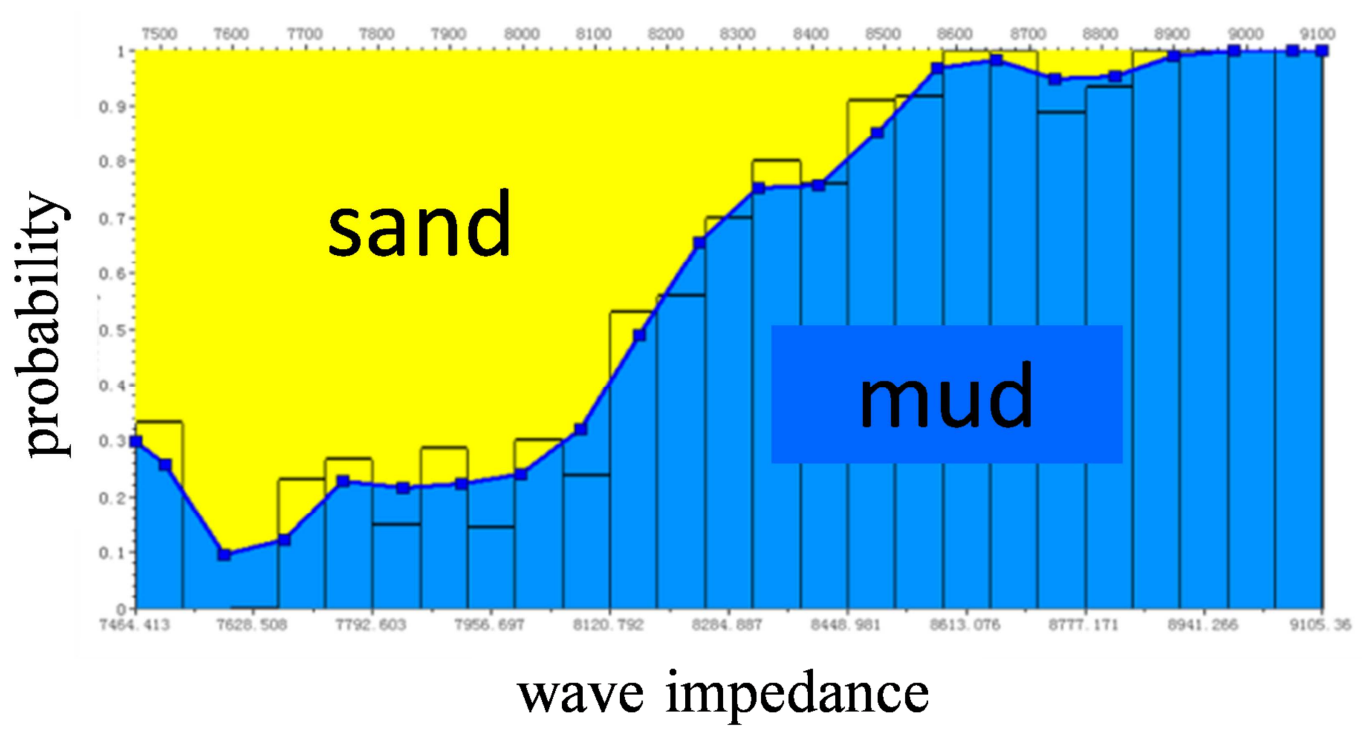

Figure 2. Based on the statistics of well point of lithology and wave impedance correlation analysis (right).

Previous studies have found that there is a functional relationship between the pressure coefficient and the formation velocity difference in the eastern region, so it is necessary to establish the layer velocity model of the whole study area before establishing the pressure prediction model. Because the logging only takes acoustic data for the target layer, the velocity of the target layer is simulated by using the same coordinate Kriging sequential Gaussian model, and the 
seismic attribute is used as the second variable to constrain the simulated variable. The equation for calculating the normal

$$
\operatorname{tr} \mathrm{V}=0.39817 * \exp (-5)^{*} \mathrm{D}^{\wedge} 2+9.6581 * \exp (-1)^{*} \mathrm{D}+1.5019 * \exp
$$

and trV: trend layer velocity (m/s), D: depth (m).

Based on the calculation equation of normal velocity trend line, the normal velocity model of $\mathrm{M}$ gas field is established. the simulated layer velocity model is subtracted from the calculated normal layer velocity model, and the velocity difference model of the whole study area is established, the data of well point velocity difference and pressure coefficient.
In the study area are analyzed, and the function formula of pressure coefficient and velocity difference is obtained by fitting (Figure 3), then the velocity difference model is calculated according to the function relation obtained by fitting, and finally the pressure coefficient model of the whole study area is obtained.

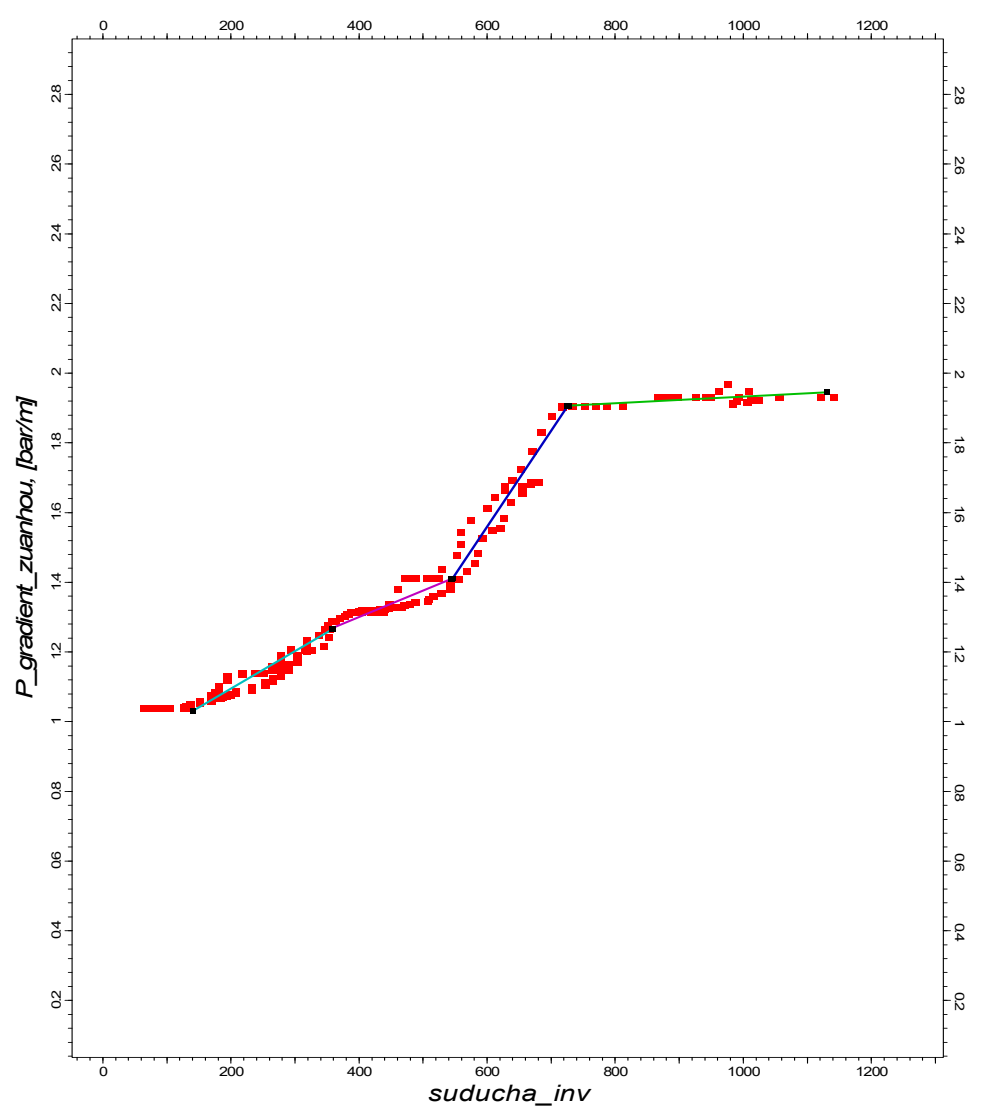

Figure 3. The pressure coefficient and differential speed figure.

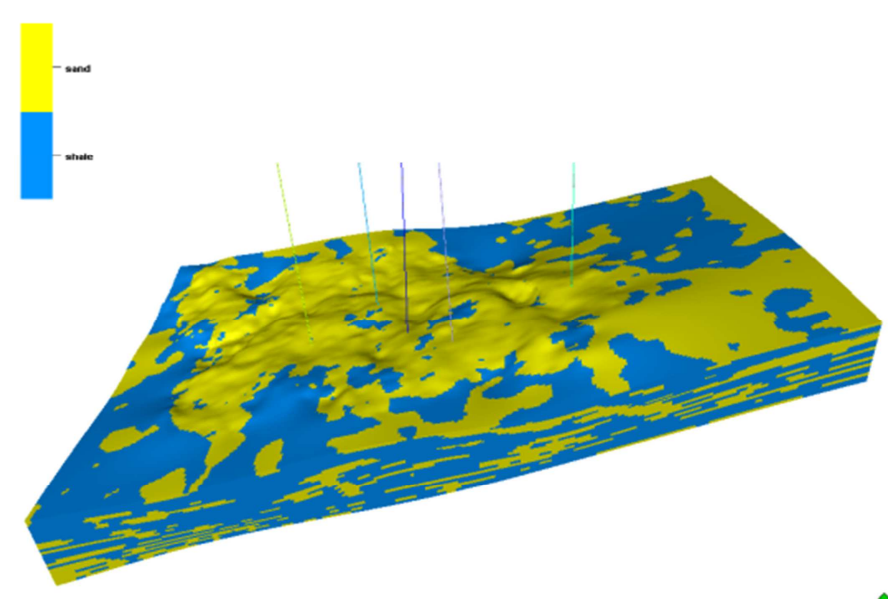

Figure 4. Lithology model is established by using interpolation method. 


\subsection{Establishment of Lithologic Model}

According to the analysis of regional data, the formation pressure is sensitive to lithology, and the formation pressure changes greatly under different lithology. the lithology based on well data statistics has a good correlation with seismic wave impedance inversion attributes, and the probability of mudstone increases when the wave impedance increases (Figure 2). therefore, sand and mudstone identification can be carried out using wave impedance constraints. the establishment of lithologic probability model is a sequential indicator simulation using seismic wave impedance inversion attributes as trend constraints [7]. The lithologic probability model established by wave impedance constrained logging method is more accurate than the lithologic model obtained by direct logging data interpolation method, and the sand body continuity is better and the sand body distribution law is closer to the geological understanding (Figure 4).

\subsection{Model Analysis and Testing}

The pressure coefficient model is tested by well exploration. The predicted pressure coefficient curve is consistent with the measured pressure coefficient curve. From the prediction results, it can be concluded that the pressure coefficient increases gradually with the deepening of the depth and the range of accelerates, Final and accurate prediction target layer pressure coefficient is 1.72 1.97 (Figure 5).

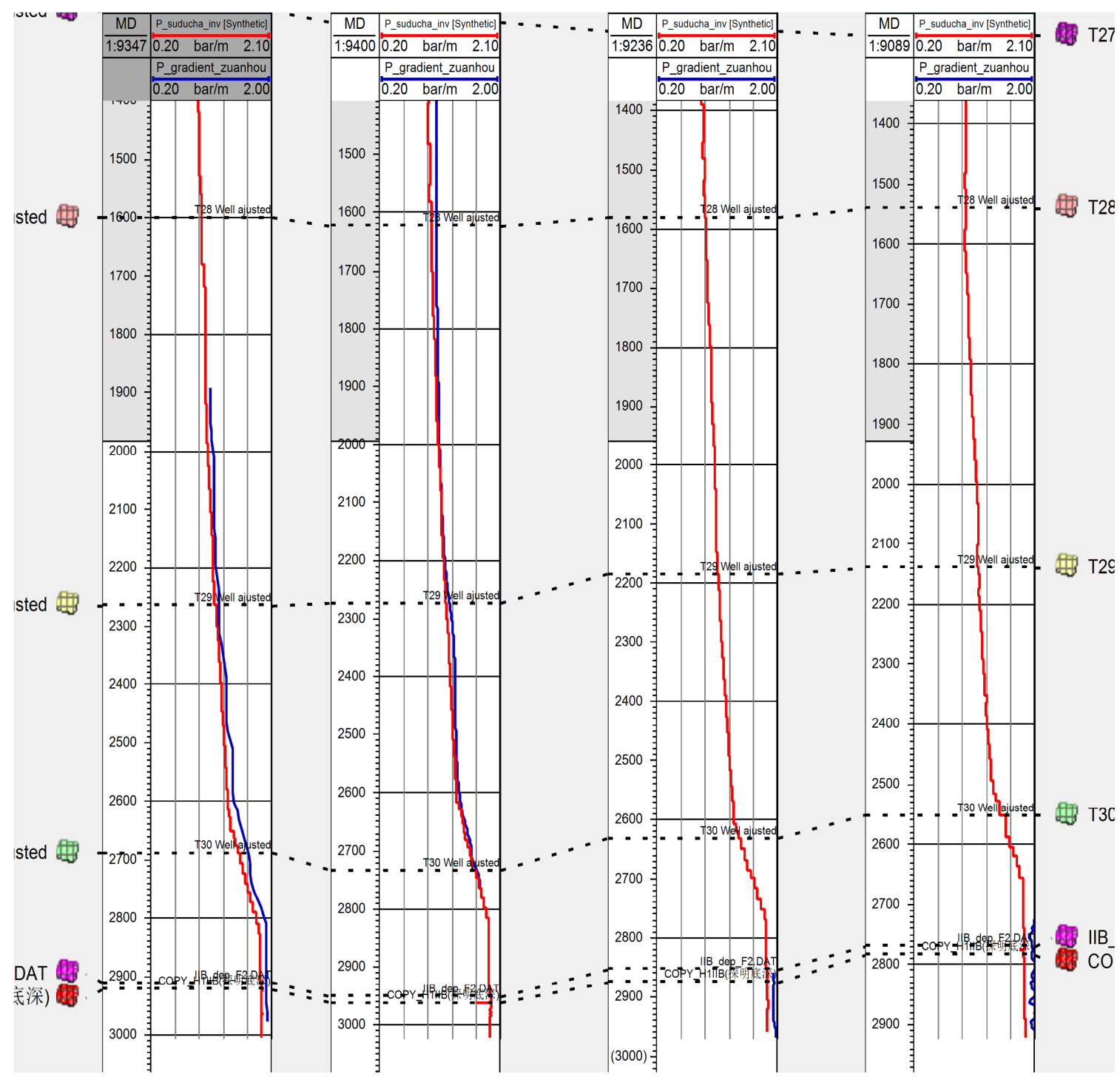

Figure 5. Test wells pressure coefficient model.

\section{Fine Implementation System}

The submarine fan system in this area is not consistent with the classical submarine fan model, and it has no obvious fan sub-facies differentiation, but is a fine grain size, short extension, small scale, rapid change of submarine fan-like sedimentary system, which shows a thick accumulation of waterway sand body combination [8]. In the process of implementation, it is revealed that the gas-water relationship is very complicated, and the water top is several tens of 
meters higher than the gas-water interface. The traditional gas-water relationship model is subverted. It shows how to characterize sand body shape effectively, and how to distinguish fluid property accurately is an important link of success or failure.

\subsection{Fluid Identification During Implementation}

A well is a directional development well, and its well location is located in the high part of the original pure gas zone of $\mathrm{H}_{1} \mathrm{~A}$ sand body. The abnormal characteristics of gas measurement in $\mathrm{H}_{1} \mathrm{~A}$ gas group are obvious, the $\mathrm{Tg}$ is about $3 \%$, the anomaly multiple is 30 , and the neutron and density have "mirror image" intersection characteristics, which have gas-bearing characteristics. but the resistivity is low, about 4ohm.m, and the electrical properties are characterized by water content (Figure 6).

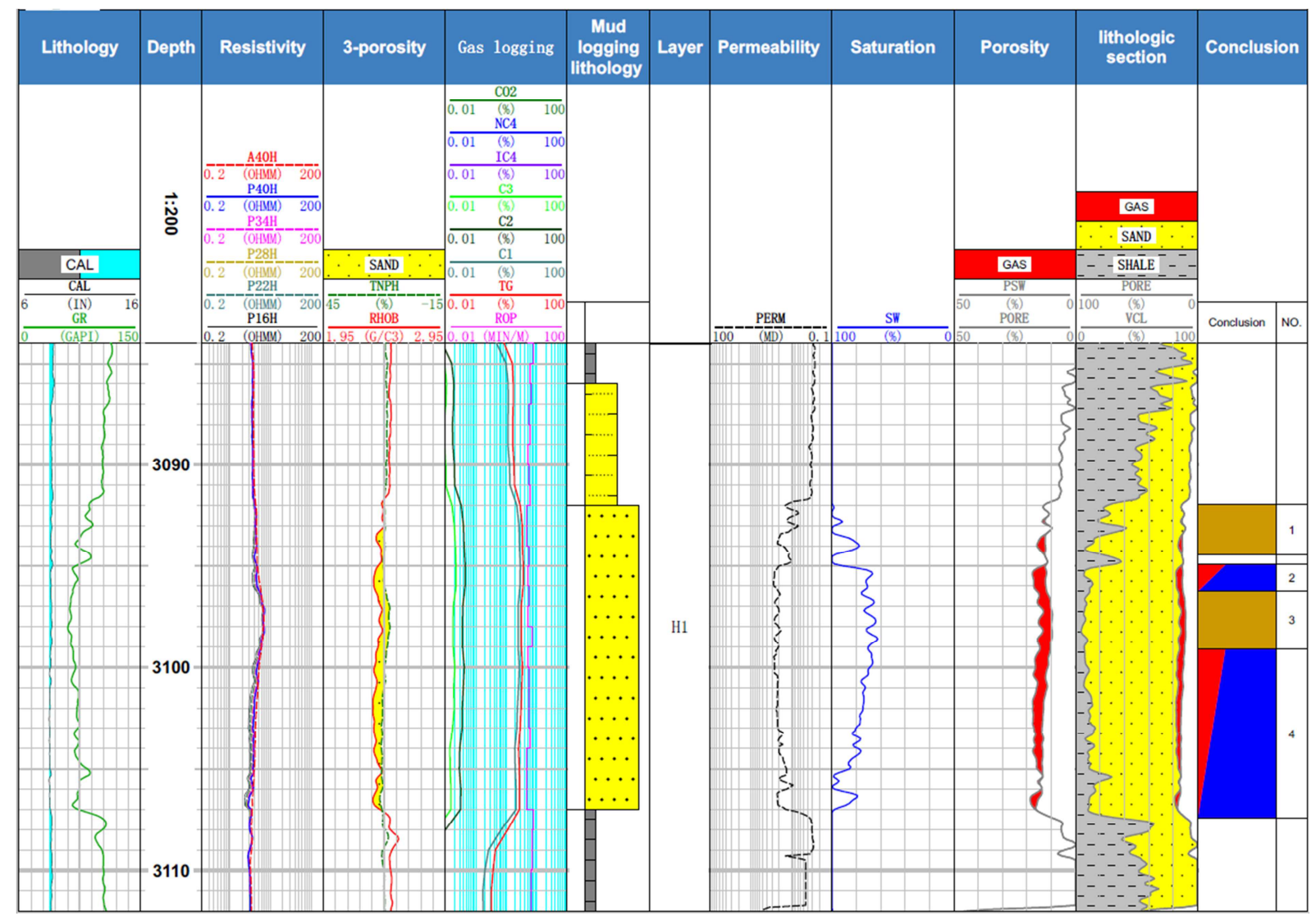

Figure 6. A well logging response characteristics.

The logging quality of A well is first checked, which is the histogram distribution of mudstone density and resistivity in the upper part of regional a gas formation. the measured value of A well is consistent with that of regional adjacent well, which proves that the logging quality of A well is reliable. reservoir parameters of A well are carefully calculated. according to the reservoir classification criteria, the reservoir of this well is judged to be II type reservoir [9]. Porosity and resistivity values of the A well exit section are projected to the regional II type reservoir fluid identification map plate. shown in figure 7, it can be seen that the well falls in the water layer area, so the well is interpreted as an aquifer (Figure 7).

\subsection{Fine Characterization of Sand in Implementation}

B well is drilled with $\mathrm{H}_{1} \mathrm{~B}$ sand body and located in the high-position pure gas zone. After drilling, it is shown that the drilling is an aquifer. The main part of $\mathrm{H}_{1} \mathrm{~B}$ sand body is drilled by $\mathrm{D}$ well, $\mathrm{E}$ well and development well. In addition to the erosion tip in the western part of the sand body, the other areas are normal sedimentary tip, and the top surface of the reservoir is reflected as a continuous strong trough, and the tip is clearly extinguished (Figure 8). The interior of the sand body also has a waterway development, showing elliptical distribution (Figure 9). B well drilling $5.7 \mathrm{~m}$ sand layer, the wave impedance inversion profile shows that the well is a separate set of thin sand body which is not connected with the main body (Figure 10). It is also confirmed by $\mathrm{CH}$ well drilling that the $\mathrm{H}_{1} \mathrm{~B}$ sand body and the sand body where the well is located have completely different gas-water interface and are two independent gas reservoir systems. These two sand bodies are two independent sand bodies. 


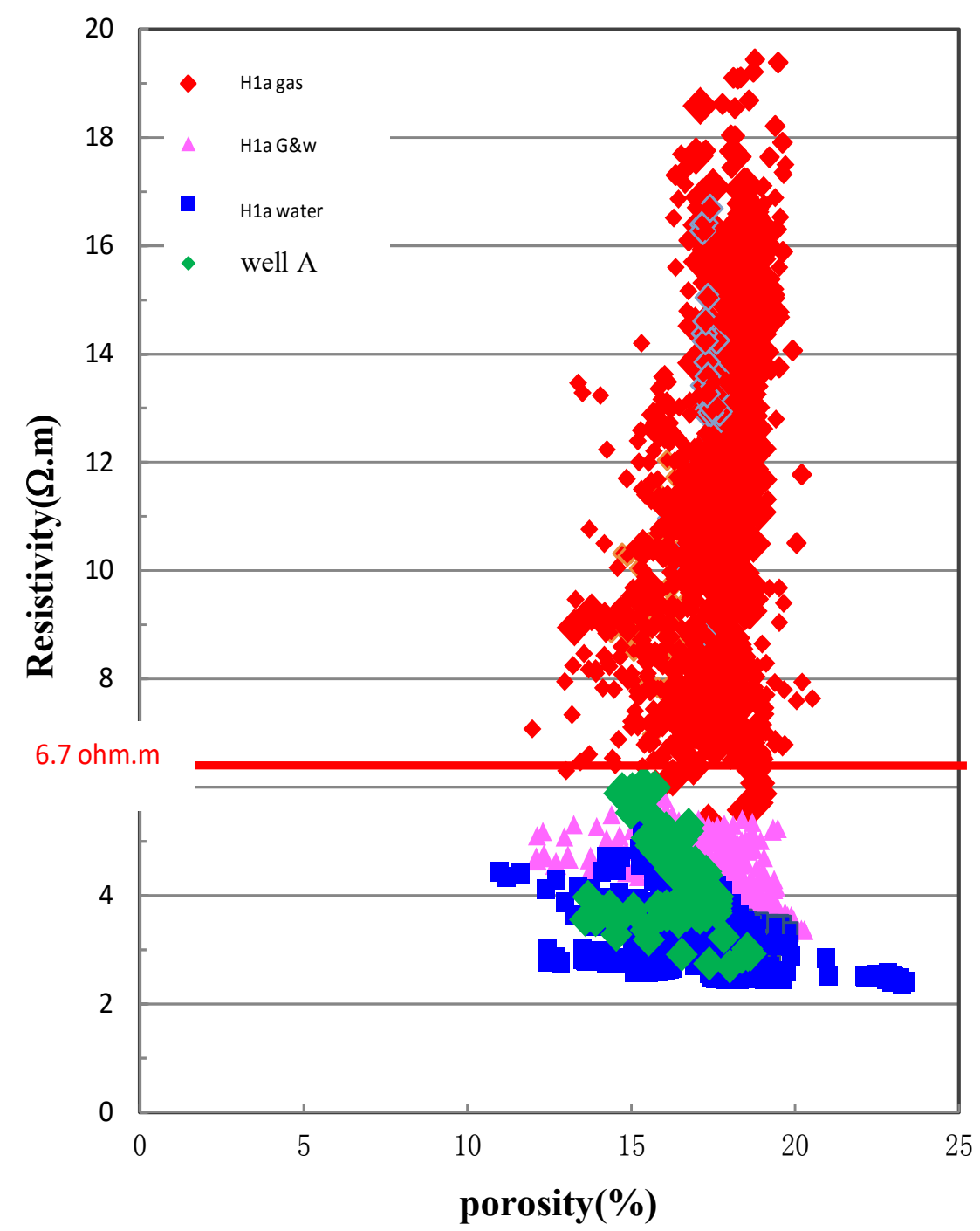

Figure 7. A well logging response characteristics of the figure.

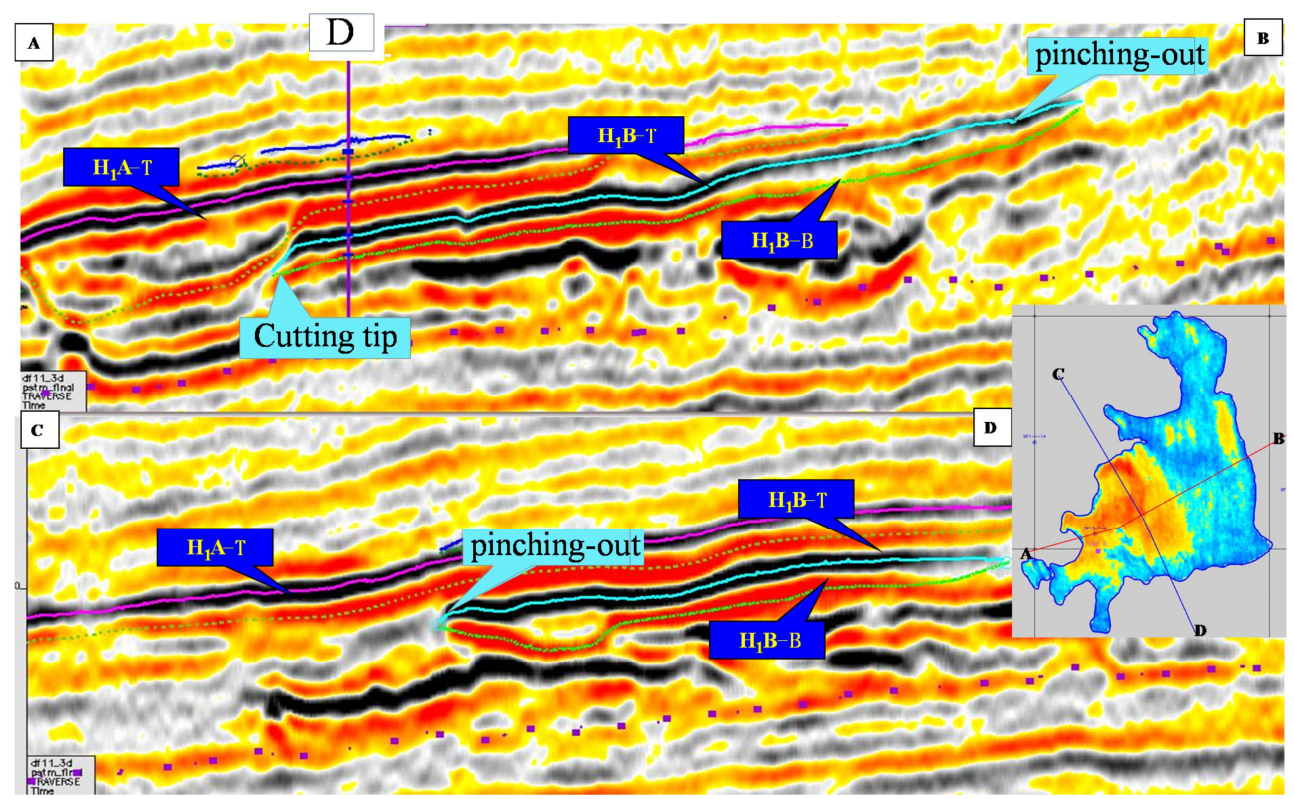

Figure 8. The Seismic interpretation profiles of $H_{1} B$ sand. 


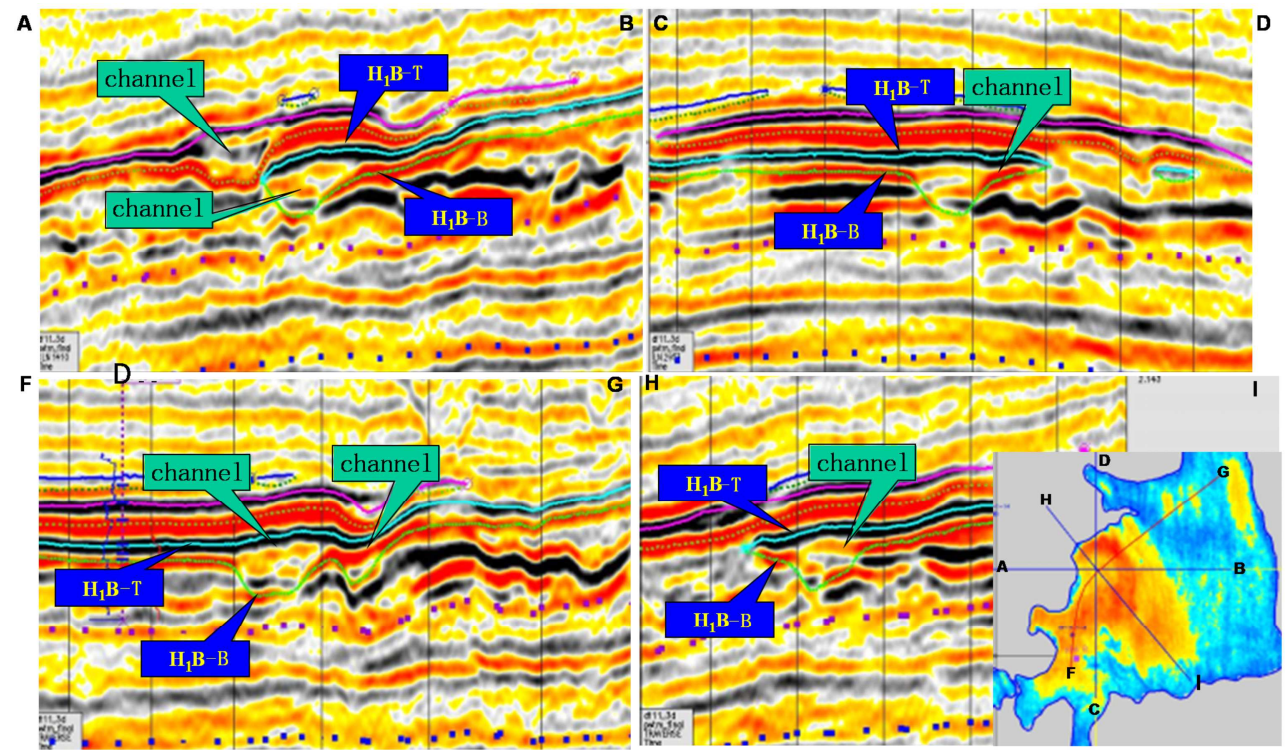

Figure 9. The cross section of $H_{1} B$ sand

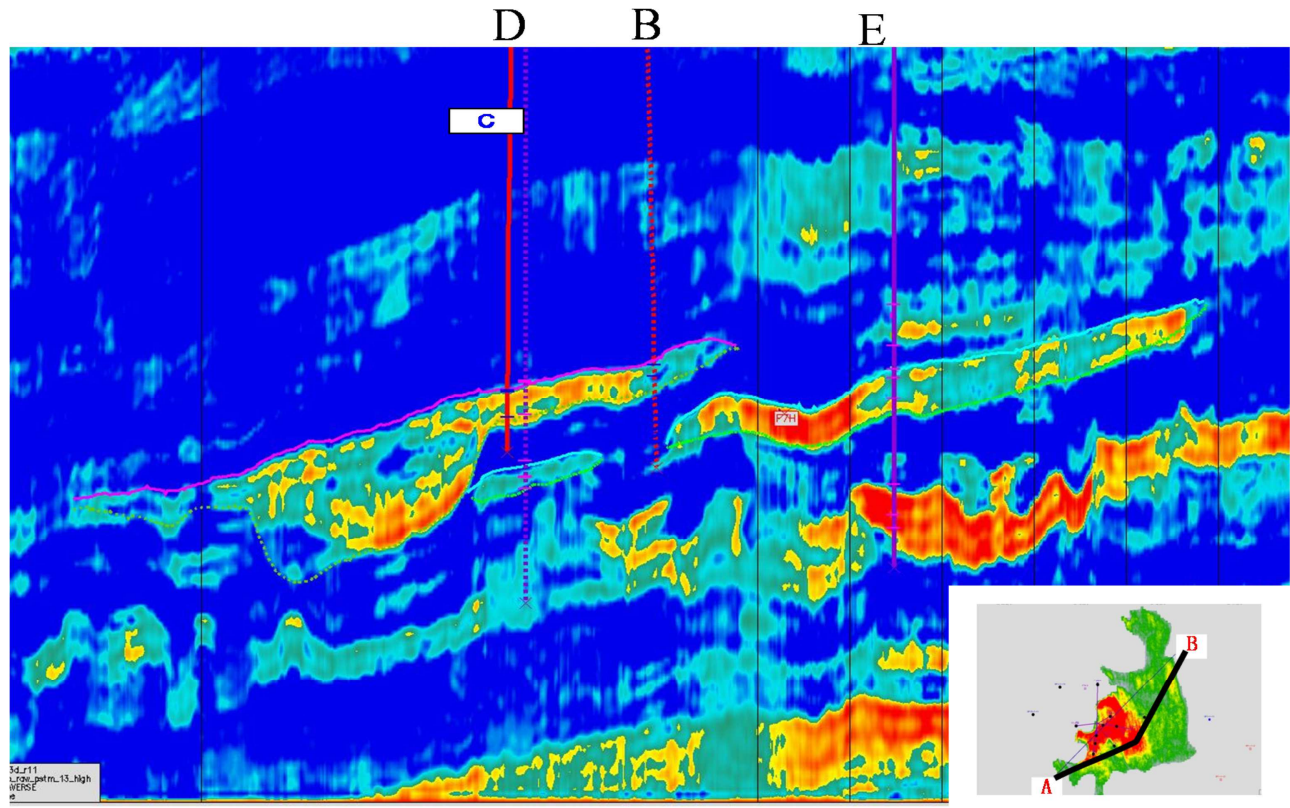

Figure 10. The wave impedance inversion cross section of $H_{1} B$ sand in $M$ gas.

\subsection{Multidimensional Analysis of Reservoir in Implementation}

The conventional reservoir has the characteristics of strong "bright spot" on the top surface of sand body, but the high temperature and high pressure gas reservoir has the characteristics of long gas-water transition zone. According to the "bright spot" of the earthquake, many wells have different geological conditions, such as dry layer, gas-water layer, aquifer, pure water layer, high-yield gas layer and low-resistance gas layer. Geophysical data are multi-solubility, so it is difficult to develop high temperature, high pressure and low permeability gas reservoir reasonably by "bright spot" identification technology alone, so it is necessary to combine geological understanding to recognize reservoir $[10,11]$.
First, from the point of view of the formation mechanism, the gas reservoir mainly depends on the diarrhea pressure of the concealed dredging system composed of low sequence secondary faults or fracture zones formed by hydraulic rupture $[12,13]$. These fracture joints are mainly the product of large Foundation activity in the eastern region, which provides a good vertical channel for the free movement of natural gas [14]. Compared with another developed gas field in the western part of the South China Sea, the reservoir formation is very young, resulting in fluid distribution may not reach equilibrium. Gas reservoir composition and gas-water distribution in $\mathrm{M}$ gas field are not uniform.

Secondly, as a whole, Dongfang $\mathrm{M}$ gas field is affected by many sets of material sources, and has the influence of

NW-SE phase of water flow [15], it is very easy to cut the 
reservoir into broken pieces, and the whole presents a longitudinal superposition, transversely connected lithologic structural gas reservoir. Based on the present seismic resolution, sand bodies are deposited in different stages from low to high, and the sand bodies are superimposed in the developed gullies. The plane and longitudinal heterogeneity is very strong (Figure 11).

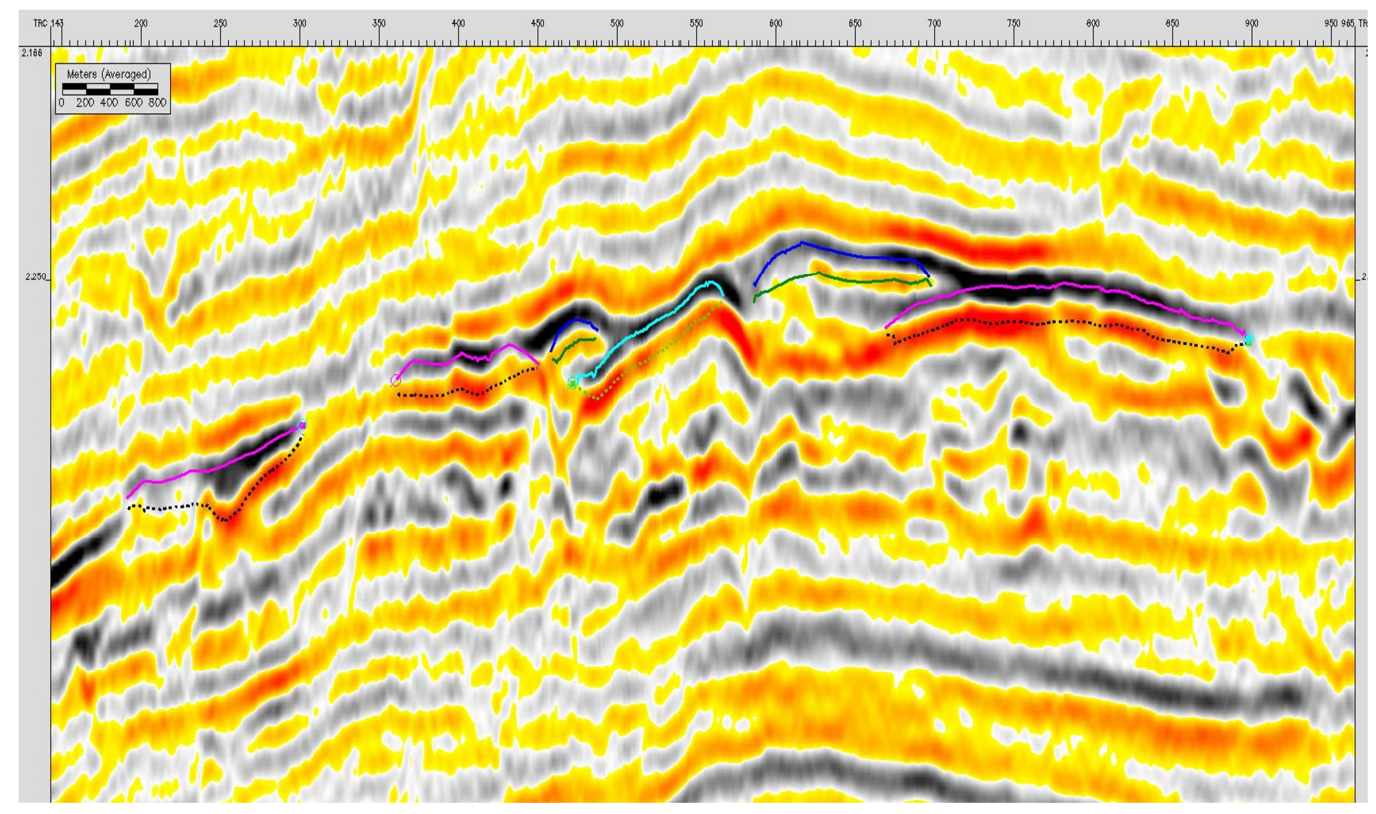

Figure 11. The figure of sand body in M gas filed.

On the basis of the $\mathrm{H}_{1} \mathrm{~B}$ sand body, a new geological model (Figure 12) was established for the reservoir and gas-bearing prediction based on the $\mathrm{H}_{1} \mathrm{~B}$ sand body (Figure 13), and accurate physical property prediction was carried out. After drilling, the $\mathrm{CH}$ well method calculated the unobstructed flow rate of 1.96 million square/per day, which was much higher than expected.

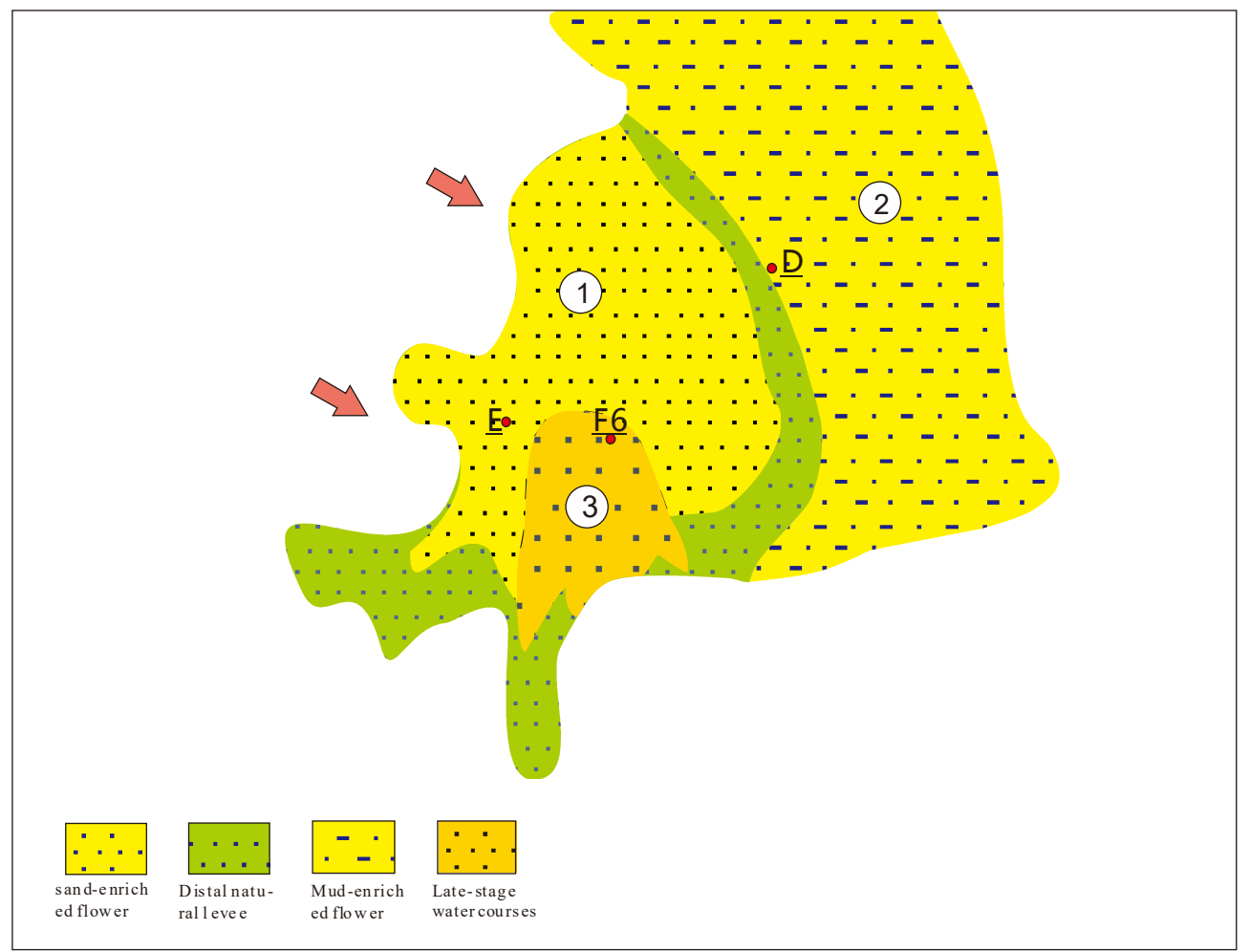

Figure 12. $H_{l} B$ sand deposition micro-facies map. 


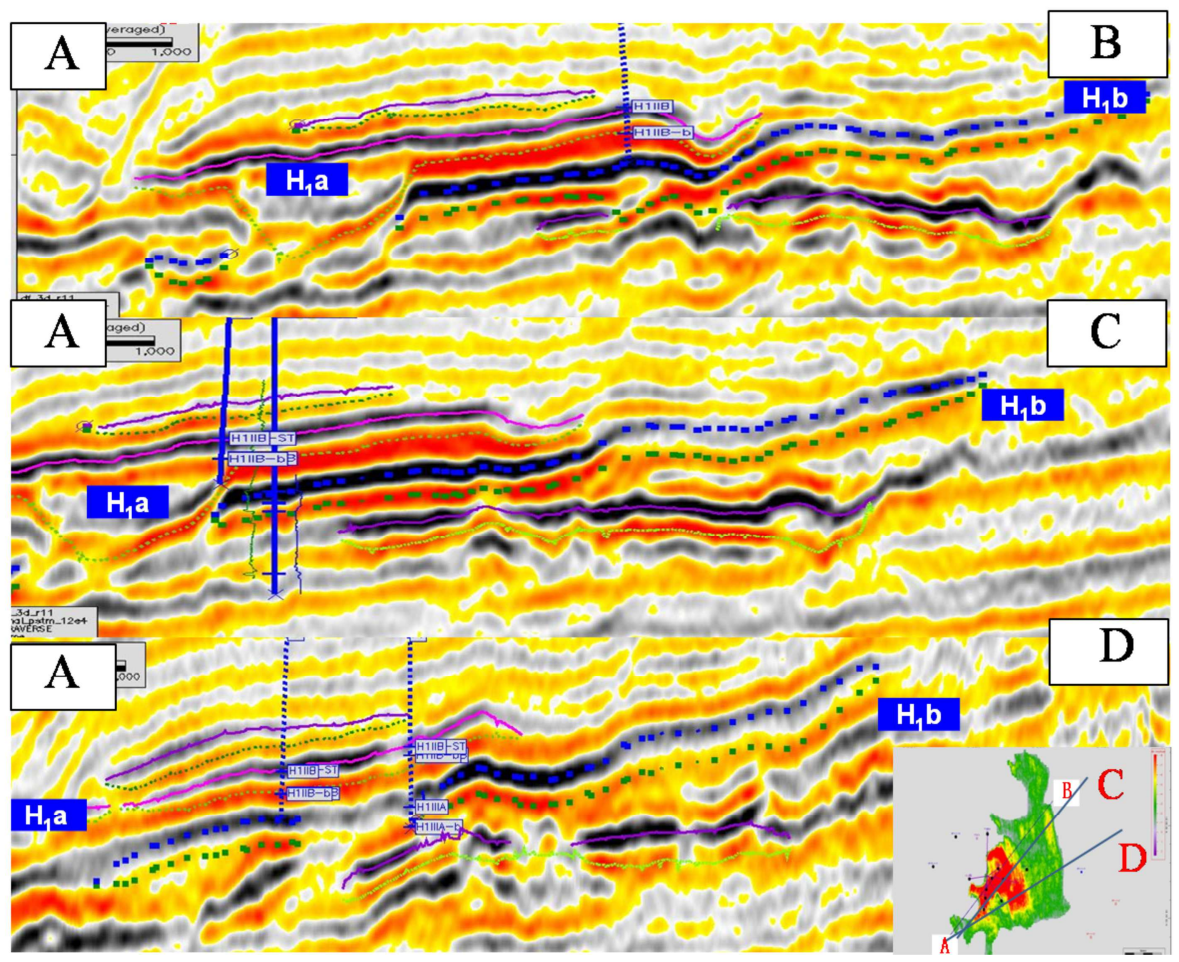

Figure 13. The figure of low position to high position sand body.

\section{Conclusions}

(1) The prediction of pressure coefficient and lithologic distribution of reservoir by using seismic inversion wave impedance property and combining deterministic modeling and stochastic simulation based on seismic property is critical for gas reservoir development at high temperature and high pressure.

(2) In the process of implementation, the corresponding log interpretation model and fluid identification plate are selected under the condition of phase control, and the reservoir is evaluated accurately.

(3) After implementation, multidimensional analysis of reservoir, from the gas content, reservoir formation mechanism, sand body characterization, fine analysis of reservoir, looking for dessert reservoir development.

\section{Acknowledgements}

This paper is supported by the National Science and Technology Major Project of China (2016ZX05024005).

\section{References}

[1] Zhongzehong, Liujinghuan, Zhangdaojun. et al. Origin and sedimentary reservoir characteristics of a large submarine fan in Yinggehai Basin, Acta petrolei, sinica. 2013, 34 (2), 103-111.

[2] Xieyuhong, Wangzhenfeng, Jiexinong, et al. Renjianye, Jiangtao, Patterns of Slope-Break Zone and Their Depositional Models in the Yinggehai Basin, 2004, 29 (5) 569-574.

[3] Fengchong, Zouhuayao, Huangzhilong, et al, Accumulation conditions and favorable areas of natural gas in central sag zone of Yinggehai basin, Journal of Central South University (Science and Technology), 2013, 44 (8), 3390-3397.

[4] Xieyuhong, Huangbaojia. Characteristics and accumulation of the Dongfang 13-2 high temperature and over pressured gas field in Yinggehai Basin, the South China Sea. Science China Earth Sciences, 2014, 44: 1731-1739.

[5] Zhangshujuan, The facies-controlled modeling in complex fault-block reservoir, China University of Mining \& Technology, 2011.

[6] Zengyijin, Fanhonghai, Zhangchuanjin, et al. A new method for detecting geo-pressare: rock mechanical parameter method. Rock and Soil Mechanics, 2005, 26 (12), 1977-1980.

[7] Zhangshulin, reflection seismic wave dynamics characteristics research of Yinggehai basin, Natural Gas Geoscience, 2001, $12(3), 10-19$.

[8] Zhongzehong, Zhangyingzhao, Hexiaohu, et al. The sequence stratigraphy od Huangliu formation and the internal structures of submarine fan in Dongfang area, Yinggehai Basin, Marine Geology \& Quaternary Geology, 2015, 35 (2), 91-99.

[9] Jiangtao, Jiexinong, Effects of High Temperature and Overpressure on Reservoir Quality in the Yinggehai Basin, South China Sea, Earth Science (Journal of China University of Geosciences), 2005, 30 (2), 215-220.

[10] Liufeng, Zhoujiaxiong, Peijiangxiang. et al. An analysis of AVO characteristics in thin gas reservoirs with a middle depth in Ledong area, Yinggehai basin, China Offshore Oil and Gas, 2014, 26 (4), 34-40.

[11] Lixuxuan, A research of seismic recognition techniques of the shallow gas reservoirs in Yinggehai Basin, Natural Gas Industry, 1999, 19 (1), 52-57. 
[12] Jiexinong, Lisitian, Huxiangyun, et al. Diapir belt heat conducting fluid system and its formation mechanism in Yinggehai Basin. Scientia Sinica Terrae. 1999, 247-256.

[13] Hejiaxiong, Xiabin, Zhangshulin, et al. Migration-accumulation of gas under the abnormal high geo temperature and superpresure circumstance in Yinggehai basin. Marine Geology \& Quaternary, Geology, 2006, 26 (4): 81-90.
[14] Jinbo, Liuzheng. Lixushen. Relationship between Accumulation of Natural Gas and Geotemperature-Geopressure System in Yinggehai Basin, Natural Gas Geoscience, 2008, 19 (1), 49-55.

[15] Jinbo, Liuzheng, Lixushen, et al. Tree-shaped conducting systems and related tree-shaped migration model of mud-fluid diapir in the Yinggehai Basin. Chinese Journal of Geology (Scientia Geologica Sinica), 2008, 43 (4): 810-823. 